\title{
Imaginação e conhecimento na escola para além da verdade científica
}

\author{
Imagination and knowledge at school beyond scientific truth \\ http://dx.doi.org/10.5007/21 78-4582.2017v51n1p056
}

\begin{abstract}
Marina Teixeira Mendes de Souza Costa, Daniele Nunes Henrique Silva, Eva Aparecida Pereira Seabra da Cruz e Patrícia Lima Martins Pederiva
\end{abstract}

Universidade de Brasília, Brasília/DF, Brasil

Tendo como base a perspectiva históricocultural, com destaque para a obra do psicólogo russo Lev Semionovich Vigotski, o presente artigo busca ampliar a reflexão teórica sobre as questões que envolvem a imaginação e o conhecimento na escola, problematizando alguns aspectos que se apresentam enraizados em nosso sistema educacional e que têm prejudicado a emergência dos processos criadores infantis. Na análise, propomos a problematização de três fatores interconectados, a saber: (a) a tradição positivista da escola; (b) a unidade compartimentalizada dos conteúdos escolares; e (c) o disciplinamento dos corpos. Notamos que, apesar dos muitos avanços e mudanças nas discussões acerca do tema e nas práticas pedagógicas contemporâneas, ainda temos um modelo de ensino que tende a não privilegiar os processos de imaginar e criar na infância, trazendo prejuízos ao longo do desenvolvimento subjetivo.

Palavras-chave: imaginação; conhecimento; escola; desenvolvimento infantil.
Based on a cultural and historical perspective, especially on the works of Russian psychologist Lev Semionovich Vigotski, the purpose of this article is to expand the theoretical thoughts on the topics that involve imagination and knowledge at school, challenging some deep-rooted aspects of our educational system that have threatened the emergence of children's creative processes. In the analysis, we propose challenging three interconnected factors, namely: (a) the school's positivistic tradition; (b) the compartmentalized unit of school subjects; and (c) the disciplining of bodies. Moreover, despite the many advances and changes in discussions regarding this topic and in contemporary pedagogical practices, we still have relied on a teaching model that shrinks imaginative and creative processes during childhood and damages subjective developments over time.

Keywords: imagination; knowledge; school; child development.

\section{Introdução}

Este trabalho, fundamentado na perspectiva histórico-cultural, é fruto de nossas críticas acerca dos espaços limitados conferidos aos processos criadores infantis na escola (ANDRÉ, 2008; BESSA; MENDES, 2012; EÇA, 2010; GOMES; NOGUEIRA, 2008; MAGALHÃES; PONTES, 2002). Em consonância com pesquisas recentes sobre o tema, concordamos que as crianças, muitas vezes, têm tido poucas oportunidades dentro da escola para realizarem suas atividades criadoras, sendo estas restritas, comumente, às aulas de artes e afins. De fato, os processos de imaginar e criar ainda ocupam um lugar marginal na escola e, consequentemente, na formação dos alunos.

Conforme Silva, Guimarães, Vieira, Franck e Hippert (2005) afirmam:

De maneira geral, parece não interessar, nos tempos atuais, o que e de que forma a criança pode ser capaz de criar, mas sim o 
que é capaz de reproduzir. O saber escolar valoriza certos processos específicos, muitas vezes opostos ao da linha da criação e da tradição. (p. 86).

Esta situação nos convoca a pensar sobre a necessidade de uma educação mais comprometida com as questões que envolvem a atividade criadora, para além da prevalência do conteúdo disciplinar, conforme abordaremos adiante. Lev S. Vigotski (1896-1934), pensador bielo-russo, já sinalizava, no início do século XX, a importância de uma educação estética que estivesse menos instrumentalizada e menos submetida à aquisição de algum tipo de conteúdo (VIGOTSKI, 2003).

Comumente observamos as crianças brincando, desenhando, contando histórias e reinventando o mundo. A partir de associações e dissociações das impressões do real, afirma Vigotski, elas compõem seu universo imaginativo, expressando diferentes maneiras de interpretar a cultura circundante (CAVATON, 2010; COSTA; SILVA; SOUZA, 2013; CRUZ, 2015; LEITE, 2004; SILVA; COSTA; ABREU, 2015). Nessa linha argumentativa, para os autores contemporâneos da abordagem histórico-cultural, a atividade criadora caracteriza o desenvolvimento infantil e precisa ser garantida nos espaços institucionais que se dedicam ao cuidado e à educação das crianças. Por isso, indagamos: por que a escola brasileira, de uma forma geral, tem se consolidado historicamente como espaço que não tem privilegiado a experiência criadora? Por que a relação entre imaginação e conhecimento se manteve de forma tão bifurcada, contribuindo para os mecanismos de exclusão dos processos criadores infantis na escola?

Para discutirmos tais questões, abordaremos três aspectos que se apresentam, em nosso entendimento, como fatores importantes para a compreensão da problemática suscitada tendo como foco as pesquisas desenvolvidas no Brasil, quais sejam: (a) a herança da tradição positivista na escola; (b) a unidade compartimentalizada dos conteúdos escolares; e (c) o controle disciplinar dos corpos. Esses temas já foram amplamente debatidos no campo das Ciências Humanas e Sociais (CALVO, 2014; FOUCAULT, 1999; GEEVERGHESE, 2016; ILLICH, 1985; LÖWY, 1987, 2003; TIRIBA, 2008), mas buscaremos entretecê-los de forma a colaborar para uma reflexão crítica acerca da relação entre imaginação e cognição, interligando-os à dimensão sensível do desenvolvimento, que é própria da atividade criadora infantil.

\section{A tradição positivista da escola}

Consolidada no século XVIII, a escola de modo geral, apesar de algumas práticas inovadoras (ABRAMOVAY, 2004; GRAVATÁ; PIZA; MAYUMI; 
SHIMAHARA, 2013), ainda está presa às tradições positivistas. O positivismo, de acordo com Michael Löwy $(1987,2003)$, baseia-se em três argumentos centrais: objetividade; neutralidade; e o princípio epistemológico que compara as pesquisas em Ciências Naturais a Ciências Humanas e Sociais como forma de se alcançar a verdade científica. Historicamente, surgiu como uma utopia revolucionária que, ao se contrapor aos ideários do absolutismo, argumentava a favor de um modo de produção de conhecimento deslocado da penumbra idealista.

Nessa perspectiva, a compreensão do homem e do meio físico coincide. Por isso, o pesquisador deve ater-se ao que é passível de ser mensurado e observado (GONÇALVES, 2010). O foco é a busca pela verdade absoluta; destituída de paixões (LÖWY, 1987, 2003; SILVA; TEJERINA; BARBATO, 2010).

Dessa forma, é firmada a primazia da neutralidade científica para pretensas conclusões fidedignas do objeto que se investiga. Seja na Astronomia, na Física, na Química, seja em outra área do conhecimento, o objetivo da pesquisa é apenas a descoberta do funcionamento mecânico e isolado do fenômeno. Segundo a visão positivista, o que ocorre na sociedade independe da vontade humana, sendo as leis naturais invariáveis e, portanto, não passíveis de transformação (LÖWY, 1987, 2003).

Tonet (2013) nos faz lembrar que:

O tronco positivista, em sentido amplo, partia do pressuposto de que havia uma homologia entre natureza e sociedade, sendo esta última regida por leis tão invariáveis como aquelas da natureza. Por isso, propunha tratar os fenômenos sociais do mesmo modo como são tratados os fenômenos naturais. (p. 56-57).

No que tange à educação escolar, o projeto positivista, embora não exclusivamente, advoga que o saber se caracterizava como instrumento de suma importância para a construção da vida. Nesse aspecto, o conhecimento é compreendido como aquele de caráter eminentemente científico (FÁVERO, 2005; SILVA, 2004). Daí advém a ideia de que o problema da verdade está no cerne da missão institucional educacional, a saber: democratizar um saber sistematizado, planejado e científico, produzido ao longo da trajetória humana (MORGADO, 2013; SANTOS; RAMOS, 2013).

Calvo (2014) explica:

La sobrevaloración de la razón y la consciencia en la escuela tiene algunas consecuencias dañinas al relegar a un segundo plano a la intuición y la emoción o simplemente ignorarlas. No cuestiono la importancia ni el papel central que la razón y la consciencia han desempeñado en el desarrollo de la ciencia. 
Sin embargo, el progreso científico no descansa exclusivamente en ellas, sino que han sido secundada por la intuición que les ha sugerido pistas sutiles que la rigurosa y exigente metodología cientifica no permite reconocerla. (CALVO, 2014, p. 70).

A ideia equivocada de que a criação é ilusória e, portanto, distante da realidade remonta dualismos descartianos ainda não superados na contemporaneidade (SILVA; TEJERINA; BARBATO, 2010). A oposição binária epistemológica imaginação x cognição (ou simulacro x realidade), por exemplo, ainda sustenta pressupostos científicos que defendem a premissa de que a produção científica é, por excelência, apreensão da verdade.

Os desdobramentos desses artífices nas práticas pedagógicas são prejudiciais porque têm trazido prejuízos - porque não dizer; atrofias, termo problematizado por Silva (2012) e Moreira (2015) - ao desenvolvimento das crianças. A racionalidade científica, divulgada prioritariamente nos conteúdos formais da escola, sacraliza o saber tecnicista e mecânico, impondo um ritmo à experiência escolar de controle e restrição dos processos criadores e imaginativos de professores e alunos (CRUZ, 2002). Essa dicotomia, que acaba por colocar em segundo plano os processos criadores, fica evidente quando analisamos os currículos que circunscrevem o sistema educacional brasileiro.

\section{A unidade compartimentalizada dos conteúdos escolares}

Os problemas enfrentados pela interseção entre imaginação e conhecimento nas práticas pedagógicas no Brasil também se vinculam ao campo da construção curricular, mais especificamente o da compartimentalização dos conteúdos. Àquela ideia de cientificidade e de objetividade própria da concepção positivista do conhecimento está acoplada a concepção de que os saberes precisam ser ensinados de forma estanque (Matemática, Química, Física, Biologia, etc), como se não tivessem nenhuma relação entre si.

Illich (1985) adverte que a escola busca fragmentar a aprendizagem em matérias a fim de construir um currículo em blocos previamente fabricados e, a partir desses conhecimentos escolhidos, realiza uma avaliação de cunho meritocrático. Para o autor, a escola quantifica o saber e, aos poucos, solidifica a ideia de que aquilo que não pode ser medido caracteriza-se como secundário, de menor valor. A instituição escolar, segundo o autor, comercializa o currículo, caracterizando-o como um bem de consumo, tal como outras mercadorias, tendo o professor que assumir o papel de distribuidor de um produto. Em uma relação semelhante àquela das mercadorias produzidas em uma fábrica, Illich esclarece que os responsáveis pela educação escolar criam o currículo com 
base em uma pesquisa científica, fundamentada nas demandas futuras, estabelecendo previamente as ferramentas necessárias para sua execução dentro de um determinado orçamento.

Nesse aspecto, o professor tem seu papel reduzido à execução de algo que já está pronto e acabado. Ele distribui o conhecimento e cabe ao aluno consumir (ou não) tal mercadoria. Em outras palavras:

O resultado do processo de produção curricular assemelha-se ao de qualquer outro processo mercadológico moderno. É uma embalagem de significados planejados, um pacote de valores, um bem de consumo cuja "propaganda dirigida" faz com que se torne vendável a um número suficientemente grande de pessoas para justificar o custo de produção. Ensina-se aos alunosconsumidores que adaptem seus desejos aos valores à venda. (ILLICH, 1985, p. 54).

Illich (1985) ainda destaca que os programas curriculares estão sempre em busca de mais instrução, embora isso não signifique que a aprendizagem aconteça de fato. O que ocorre é que a disciplina se apresenta embrulhada para ser consumida em um determinado tempo. As ofertas curriculares variam de um ano para outro, tornando-se, muitas vezes, obsoletas para o consumo. O objetivo do sistema escolarizado de sociedade, então, centra-se na aquisição de blocos de conhecimentos isolados.

Com a divisão do conhecimento, tornou-se possível a fragmentação do tempo na escola, ou seja, em cada determinado período é estabelecido uma disciplina para ser ensinada. Desse modo, por meio do currículo e de sua segmentação no tempo, ocorre o controle da instituição escolar. Controla-se o professor naquilo que ele ensina e, consequentemente, o aluno. Determina-se o conhecimento a ser ensinado; o tempo destinado àquele conteúdo; em que velocidade se deve aprender; os materiais didáticos utilizados etc. Além disso, ainda, se engessa o resultado do processo (GALLO, 2000; TUNES, 2011).

Sabemos que, nos últimos 20 anos, existem trabalhos científicos que têm abordado a necessidade de um currículo interdisciplinar. Thiesen (2013) defende a urgência de se adotar a interdisciplinaridade na constituição do currículo não apenas em seu aspecto exterior, enquanto método mas também como princípio, buscando romper com a tradição positivista. Segundo o autor,

[...] a interdisciplinaridade deve ser entendida num duplo aspecto: como movimento do real, portanto na gênese da produção histórica do mundo e do conhecimento, e como exigência científica que busca certa organização do mundo e do conhecimento por intermédio das linguagens. (THIESEN, 2013, p. 593-594 - negrito nosso). 
Ao trazer a mediação pelas 'linguagens', Thiesen (2013) está chamando a atenção para o campo de expressão e representação do real que não são exclusivos da ciência positivista. Aqui, ao nosso ver, abre-se uma possibilidade para pensar sobre a criação na escola como esfera de produção de conhecimento, reveladora de modos de compreender o mundo em suas diversas e contraditórias linguagens (SILVA; ABREU, 2015). Tal possibilidade é fundamental para promoção de processos cognitivos que colocam o homem diante da tarefa intransferível de, em contato com a realidade (e com o outro), pensar de forma plural sobre si mesmo.

Sabe-se, contudo, que as práticas pedagógicas que envolvem a criação se restringem, muitas vezes, às datas comemorativas, festas específicas, atividades pontuais e extracurriculares. Nos cursos de pedagogia, por exemplo, as disciplinas teóricas pouco se articulam à prática criadora do educando, no que tange ao lúdico e à arte (CANDA; BATISTA, 2009). Dessa maneira, são privilegiados os conhecimentos pedagógicos em que os conteúdos possam ser dados de maneira estanque, fragmentária, conforme a orientação positivista. As ações criadoras, que envolvem processos criadores e autorais, são ignoradas.

Apesar desse cenário, é importante sinalizar que, no campo da arte e da educação, iniciativas têm sido desenvolvidas com o intuito de diminuir o fosso que separa os processos criadores das atividades regulares privilegiadas na escola. Há investimentos investigativos importantes em andamento cuja temática versa sobre: (a) arte, mediação cultural e educação (BUCHMANN, 2014; MARTINS, 2014); (b) produção de imagens e atividades criadoras na escola (SCHWEDE; ZANELLA, 2013; SILVA, 2012; SOUZA, 2002); (c) atividades criadoras como mediadoras da produção de conhecimento (MAHEIRIE; SMOLKA; STRAPPAZZON; CARVALHO; MASSARO, 2015; PUPO, 2011; SCHROEDER; SCHROEDER, 2011) etc. De forma mais ou menos explícita, as pesquisas apresentam alternativas para o campo da arte e da criação na escola, ao proporem rupturas na organização tradicional do currículo, integrando vários campos do saber e relacionando-os a setores da arte, como o teatro, a poesia, a música, a fotografia etc.

Estamos longe, porém, de resolver os limites da tradição positivista na escola e suas implicações e desdobramentos. A situação é agravada pelo controle do currículo, conforme indicamos, associado ao controle dos corpos, como será discutido a seguir.

\section{O controle dos corpos}

Como resultado do conteúdo disciplinar e de uma rotina escolar fixa, os corpos são contidos e disciplinados. A ideia de controle não surgiu na escola, 
mas reflete os princípios de uma sociedade capitalista industrial. Isso porque, à medida que os processos de industrialização foram se desenvolvendo e se impondo, o corpo foi se constituindo, domesticando-se, como meio de produção. Ou seja: o corpo se tornou coisa, coisificou-se, passou a ser compreendido como plataforma para o trabalho; algo que precisa ser moldado, controlado e tornado submisso (COSTA; SILVA; SOUZA, 2013; PRADO; TRISOTTO, 2008; UGARTE, 2005).

Tal como Marx e Engels (2010), em sua obra Ideologia Alemã preconizaram, ao retratar o período de industrialização no Brasil, Bercito (2011), por exemplo, lembra que o homem teve como seu primeiro instrumento de trabalho o corpo. Os movimentos realizados, a força muscular, as habilidades corporais específicas possibilitaram ao homem sua interação com a natureza, a ponto de transformá-la para suprir suas necessidades básicas (como, por exemplo, aquelas relacionadas à alimentação).

No capitalismo industrial, a transformação do corpo do trabalhador em mera ferramenta de trabalho avança com foco na produtividade. Procura-se, assim, moldar e padronizar os comportamentos, legitimando posturas e gestos como adequados para responder às exigências das demandas da máquina, da industrialização. Ainda segundo Bercito (2011), nesse sistema visa-se à construção do corpo-ferramenta, concebido como instrumento reduzido à força de trabalho. Ou seja: o corpo, no capitalismo, passa a ser visto apenas como mais um elemento na engrenagem; uma mercadoria utilizada para gerar outras mercadorias. As técnicas corporais se destinam a empregar a energia naqueles movimentos específicos e repetitivos, em busca da exatidão e da eficiência. Desse modo, corpo e mente se apresentam separados, desconectados, e o conhecimento exigido do trabalhador é aquele que possibilita que sua atividade seja produtiva. Isto é, o conhecimento está direcionado para que o trabalhador execute uma determinada ação.

O corpo, então, precisa ser saudável e, portanto, produtivo por mais tempo. Se o trabalho se torna extenuante, causando doenças físicas e/ou mentais, a medicina torna-se essencial para que o desempenho do trabalhador não seja prejudicado. Procura-se, então, estruturar racionalmente a forma como a energia deve ser utilizada no trabalho, com o objetivo de se evitar que o corpo, controlado e manipulado, deixe de servir como meio de produção eficaz (BERCITO, 2011).

Nota-se, assim, que o poder disciplinar implantado basicamente pelas normas e ações militares estava presente não somente nos quartéis e presídios, mas se instalou também nas fábricas, nos hospitais e nas escolas. Tal poder não era abstrato. Ao contrário, ele ocorreu de forma hierárquica e se materializou nos corpos dóceis e manipuláveis (MACHADO, 2011; SOUZA, 2001). 
Nas palavras de Michel Foucault:

O momento histórico das disciplinas é o momento em que nasce uma arte do corpo humano, que visa não unicamente o aumento de suas habilidades, nem tampouco aprofundar sua sujeição, mas a formação de uma relação que no mesmo mecanismo o torna tanto mais obediente quanto é mais útil, e inversamente. Forma-se então uma política das coerções que são um trabalho sobre o corpo, uma manipulação calculada de seus elementos, de seus gestos, de seus comportamentos. (FOUCAULT, 1999, p. 119).

Machado (2011) identifica quatro argumentos que caracterizam o modo de organizar a sociedade segundo os pressupostos da disciplinarização dos corpos. O primeiro refere-se à organização do espaço. Como forma de distribuir os indivíduos, acaba-se por dividi-los de maneira a classificá-los e isolá-los em espaços hierarquizados, em funções distintas, a depender do que lhes é exigido. $\mathrm{O}$ segundo diz respeito à necessidade de o corpo estar condicionado a cumprir uma função específica em um determinado tempo; a relação entre o tempo e a produção é controlada. Em terceiro, tem-se a vigilância permanente, essencial para se prezar pela primazia da disciplina. Por fim, o poder disciplinar, ao mesmo tempo em que controla, gera conhecimento. Isso porque é preciso um contínuo registro daquilo que fora observado para ser apresentado para as altas hierarquias dominantes.

Qualquer semelhança com a escola, enquanto instituição social inserida no sistema capitalista, não é mera coincidência. Nela, o controle do conteúdo positivista por meio da segmentação do currículo em disciplinas estanques se completa com a disciplina dos corpos.

Todavia, segundo o pensamento deleuziano, a disciplina que era imposta em instituições sociais específicas, após a Segunda Guerra Mundial, começa a ser exercida para além dos espaços físicos pré-estabelecidos (SILVA, 2011). O poder e as informações, que na sociedade disciplinar se estruturavam de modo vertical e hierárquico, com o advento da internet se expandem e alcançam uma dimensão ilimitada. Surge, então, a sociedade de controle, em que o poder é horizontal e sem localização definida (COSTA, 2004; DELEUZE, 2004).

Deleuze (2004) explica que os modelos de confinamento: escola, igreja, prisão, hospital, etc. na sociedade disciplinar são substituídos, na sociedade do controle, pela empresa. No que concerne especificamente à escola, Deleuze (2004) explica que a formação permanente - educação continuada para além do espaço físico da instituição - aponta para uma possível substituição da escolar, tal como conhecemos atualmente. Além disso, o exame é substituído 
pelo controle constante. Segundo o teórico, essa é a forma mais segura da escola se tornar empresa.

Outro fator que permeia o controle versa sobre como os indivíduos são reconhecidos. Se antes, a assinatura e a matrícula do indivíduo indicavam a posição que ele ocupava em uma determinada massa; no controle, por sua vez, ele é identificado por uma cifra, uma senha. "A linguagem numérica do controle é feita de modo a marcar o acesso à informação ou a rejeição" (DELEUZE, 2004, p. 222). Não há mais uma relação entre massa e indivíduo, mas o indivíduo passa a ser dividido em espaços que ultrapassam a materialidade de seus próprios corpos.

Nessa linha, levando em consideração os novos contornos da sociedade contemporânea, torna-se importante refletir sobre de que forma a atividade criadora vem sendo mediada no sistema educacional brasileiro. Longe de apresentarmos uma resposta definitiva, buscamos refletir acerca das práticas pedagógicas regulares, tomando como âncoras de análise os três aspectos levantados até aqui. Para tanto, decidimos por apresentar uma situação pedagógica concreta em que a verdade científica, pautada na herança positivista, contraria a verdade imaginada.

\section{A verdade positivista versus a verdade imaginada: adversidades na sala de aula}

Como destacamos, as práticas escolares estão instituídas e se instituem por meio de uma concepção sobre o que é ciência, verdade e conhecimento (SILVA, TEJERINA; BARBATO, 2010). Por isso, em caráter elucidativo, decidimos trazer uma situação de sala de aula na educação infantil com o objetivo de ampliar a reflexão sobre as questões levantadas até aqui. Tal situação foi registrada durante uma pesquisa realizada por Silva (2012) acerca da emergência dos processos criadores na escola.

\section{Episódio: O Curupira de pé direito}

Estamos em uma sala de aula da rede pública de ensino - Rio de Janeiro - com 15 alunos de 5-6 anos de idade. A professora trabalha o Folclore brasileiro e decide pegar um livro sobre a história do Curupira. Ela está em pé, de frente para as crianças, que se encontram sentadas em suas carteiras. As crianças, paulatinamente, vão se levantando, aproximam-se da professora e ficam completamente absortas na história.

Num determinado momento da história, em que se explicam as características do Curupira, a professora lê que ele gosta de fumar e beber. Ela, entre- 
tanto, parece um pouco confusa, ao falar para crianças os gostos inadequados do personagem e interrompe a história e exclama:

- Gente, essa história não é de verdade! É uma lenda! Lembra que a tia falou que a história não é de verdade, que uma lenda não existe na vida real. Isso, aqui, é tudo de mentira (aumenta o tom de voz). É mentirinha!

Gui, entretanto, questiona a professora (falando bem alto para todas as crianças ouvirem):

-... Eu nunca vi um Curupira de pé para trás, mas já vi um Curupira de pé direito.

Imediatamente, a professora comenta, com olhos bem fixos e voz bem alta para Gui:

- Onde você viu? Me fala, onde você viu?! Eu não disse que isso é de mentira?!

- Mas, eu já vi... lá onde eu moro, lá no morro.

- Me prova, onde você viu?!

Gui, muito intimidado, desconversa:

- Esquece. Continua, continua a ler...

$[\ldots]$

$\mathrm{Na}$ situação relatada, as crianças estão em sala de aula e a professora desenvolve um trabalho sobre o tema do folclore baseado nos mitos e nas lendas brasileiras. A lenda em questão é a do Curupira. Por meio da história, a professora apresenta o personagem para as crianças. Percebemos que a narrativa envolve a turma, que, aos poucos, aproxima-se da professora e do livro que está sendo lido. Ao ler a parte que descreve o comportamento de beber e fumar do Curupira, a professora parece desconcertada. Ela interrompe a história e alerta as crianças que os mitos e as lendas não são coisas reais.

Ao ouvir esse comentário, Gui contesta a professora e diz já ter visto o Curupira de pé direito onde mora. A professora, então, questiona a criança, em tom de autoridade, sobre em que lugar ele teria visto o tal Curupira. Mais ainda, pede à criança que prove tê-lo visto. Gui, sem ter como provar o fato, cala-se e pede que a professora esqueça e continue a história.

Nesse caso, temos de um lado a colocação da professora de que os mitos, as lendas não são coisas reais e, de outro, a posição de Gui. Isto é, o que é 
verdade para o aluno é falso para a professora, pois o Curupira de pé direito não pode ser comprovado, descrito e objetivado. Ele, de fato, não existe, pois é fruto da imaginação do aluno.

Além disso, o Curupira bebe e fuma, trazendo uma questão moral para a situação de aprendizagem, pois ela está intrinsicamente relacionada ao tensionamento entre a verdade científica e à verdade imaginada. De fato, é no momento em que o problema moral se explicita que a professora interrompe a leitura e afirma que o Curupira é uma lenda. É também neste momento que Gui a contradiz alegando já tê-lo visto.

Para o Vigotski, a depender do contexto sócio-histórico, cada classe social apresenta sua própria moral. Isso implica afirmar que a moral "é produto da psicologia social" (VIGOTSKI, 2003, P.209). Dessa forma, no que se refere à psicologia social, a moral é compreendida como certo modo de comportamento social, pautada a favor da classe hegemônica.

Seguindo essa linha, Vigotski $(1999,2003)$ problematiza que nem sempre as crianças concordam com a moral que o professor busca ensinar por meio de uma história, por exemplo. Dito de outro modo, a atitude do personagem, que deveria se destacar (segundo a ótica do professor), muitas vezes, não se destaca e pode ocorrer exatamente o contrário. O comportamento moral, que a princípio não é aceito socialmente, é o que a criança demonstra maior interesse. Isso parece ocorrer na situação pedagógica supracitada.

Nessa linha, Vigotski (2003) critica a instrumentalização da experiência estética. Ele se contrapõe a ideia de que a criança tem que responder de forma adequada aos objetivos instrucionais (e, também, morais) da professora e não, necessariamente, expondo sua própria opinião. Entre a professora e Gui, a experiência estética deveria versar sobre ouvir o que ele pensa e sente sobre a história contada - o comportamento do personagem, por exemplo -entendendo que o bem e o mal; certo e errado; verdade e ilusão coexistem contraditoriamente dentro de nós.

Num desdobramento, é importante ressaltar que a verdade de Gui é a sua própria criação, que se estrutura a partir da síntese - em forma de um Curupira de pé direito - de materiais sensíveis e estéticos que não necessariamente adquirem forma real e comprovável. Ou seja, as verdades subjetivas (que se encontram no campo da verossimilhança, por exemplo) estão no plano da imaginação e, lá, adquirem veracidade (para o menino).

Sobre isso, Vigotski (2003) argumenta:

A retificação e a correção [...] significa apenas uma grosseira intromissão na estrutura psicológica de sua vivência e ameaça impedi-la. Quando as linhas infantis são modificadas e corrigi- 
das estamos provocando uma confusão e perturbação na psique infantil. Por isso, é fundamental que a psicologia dê plena liberdade à criação infantil, renuncie à ideia de compará-la com a consciência do adulto e admita sua originalidade e suas particularidades. (VIGOTSKI, 2003, p. 236).

De fato, a criação infantil é resultante de experiências individuais, sociais e históricas. É um complexo processo de organização. É, acima de tudo, realidade, processo e produto de qualidades vivenciais combinadas. Por isso, Gui insiste, por um breve momento, no seu Curupira.

Contudo, ele sabe que não é possível provar a existência do seu personagem e se cala, pedindo que a professora continue a história. Isso, entretanto, não quer dizer que, enquanto imagem criada pela criança e desejosa de ser contada para o outro, o Curupira não exista para o menino. O personagem, como herói, está objetivado na narrativa que se direciona para a turma. A verdade de Gui revela-se por sua (e na sua) experiência sensível. Nesse caso,

[...] todas as nossas vivências fantásticas e irreais transcorrem, no fundo, numa base emocional absolutamente real. Deste modo, vemos que o sentimento e a fantasia não são dois processos separados entre si mas, essencialmente, o mesmo processo, e estamos autorizados a considerar a fantasia como expressão central da reação emocional. (VIGOTSKI, 1999, p. 264).

Nesses termos, vale ressaltar que a censura retratada no episódio vincula-se aos princípios epistemológicos da tradição positivista que problematizamos ao longo deste artigo, desdobrando-se no impacto dessas premissas num tipo de entrave ao desenvolvimento infantil, e consequentemente ao potencial criador.

Tais imposições e possíveis constrangimentos também reduzem as potencialidades infantis de expressão e elaboração sobre o real. Isso porque, nessas situações de possível cerceamento, a criança tende a se preocupar em responder aquilo que se espera dela. Esta expectativa caminha em direção contrária à atividade criadora defendida por Vigotski (2009); como a atividade psíquica que se refere à criação de novas imagens ou ações que se distanciam da mera reprodução.

\section{Considerações finais}

Tal como discutimos ao longo do texto, a tradição positivista está comprometida com o cientificismo e a compartimentalização de conteúdos, que relega a imaginação a um plano secundário e marginal, completando-se com o controle (direto e indireto) dos corpos para além dos muros da escola. 
A situação pedagógica explicitada neste artigo, por exemplo, revela que aquilo que é valorizado na escola é, muitas vezes, diferente e está em oposição ao que se privilegia nas atividades criadoras. O problema da verdade científica se opõe à verdade subjetiva e sensível (verossimilhança), trazendo contradições no interior da escola e prejuízos para a formação das crianças.

Concordamos com Vigotski (2003) que:

Os problemas da educação serão resolvidos quando se resolverem os problemas da vida. Então, a vida do homem se transformará em uma criação ininterrupta, em um ritual estético, que não surgirá da aspiração de satisfazer algumas pequenas necessidades, mas de um ímpeto criador, consciente e luminoso [...] O que hoje se realiza no âmbito da arte, posteriormente impregnará a vida inteira, e a vida se tornará um trabalho criador. (VIGOTSKI, 2003, p. 304).

Nesses termos, a vida compreende processos criadores no cerne da necessidade/desejo humano de estar no mundo. Por isso, é urgente a defesa de uma sala de aula com outra estrutura e função; outras intencionalidades pedagógicas organizadas em um ambiente educativo voltado para a possibilidade do exercício do ato criador.

A tarefa do professor envolve o "desenvolvimento de todos os aspectos que respiram atividade e vida" (VIGOTSKI, 2003, p. 297). Por isso, pensamos em professores e crianças que possam se reconhecer na experiência autoral e criadora porque desenvolveram e tiveram encorajados suas sensibilidades e seus modos de expressão.

Em outras palavras, pensamos em professores e crianças que não tenham obstáculos em suas experiências e atividades criadoras; que não estejam reféns de práticas pedagógicas que privilegiam a racionalidade técnica e um tipo de objetividade decorrente de uma (pretensa?!) verdade absoulta. Tal racionalidade reprime processos subjetivos e afetivos, segmentando modos de conhecer em compartimentos estanques que instaura no próprio corpo indivíduos embrutecidos.

\section{Referências}

ABRAMOVAY, M. Escolas inovadoras: experiências bem-sucedidas em escolas públicas. Brasília, DF: UNESCO, Ministério da Educação, 2004.

ANDRÉ, C. Espaço inventado: o teatro pós-dramático na escola. Educação em Revista, Belo Horizonte, n. 48, p. 125-141, dez. 2008. 
BERCITO, S. Corpos-máquinas: trabalhadores na produção industrial em São Paulo (décadas de 1930 e 1940). In: PRIORE, M. D.; AMANTINO, M. (Orgs.). História do corpo no Brasil. São Paulo: Unesp, 2011, p. 371-404.

BESSA, P.; MENDES, V. Conteúdo básico comum: ensino de arte em escolas públicas estaduais de Belo Horizonte/MG. Educação em Revista, Belo Horizonte, v. 28, n. 1, p. 313-342, mar. 2012.

BUCHMANN, L. P. Escolares nos museus: ensaio do novo público como ato político de educadores intelectuais. MIDAS, n. 3, 2014.

CALVO, C. Propensión a aprender y desescolarización de la escuela. Logos: Revista de Lingüística, Filosofía y Literatura, v. 24, n. 1, p. 66-74, 2014.

CANDA, C.; BATISTA, C. Qual o lugar da arte no currículo escolar? R.cient./FAP, Curitiba, v. 4, n. 2, p. 107-119, jul. 2009.

COSTA, M. T. M. S.; SILVA, D. N.; SOUZA, F. F. Corpo, atividades criadoras e letramento. São Paulo: Summus, 2013.

COSTA, R. Sociedade de controle. São Paulo Perspectiva, São Paulo, v. 18, n. 1, p. 161-167, Mar. 2004 .

CRUZ, M. N. Imaginação, conhecimento e linguagem: uma análise de suas relações numa perspectiva histórico-cultural do desenvolvimento humano. 2002. Tese (Doutorado) - Faculdade de Educação, Universidade Estadual de Campinas, SP, 2002.

CRUZ, M. N. O brincar na educação infantil e o desenvolvimento cultural da criança. In: SILVA, D.; ABREU, F. (Orgs.). Vamos brincar de quê? São Paulo: Summus, 2015, p. 67-89.

DELEUZE, G. Conversações. Rio de Janeiro: Ed. 34. 4ª reimpressão. 2004.

EÇA, T. Educação através da arte para um futuro sustentável. Cadernos CEDES, Campinas, v. 30, n. 80, p. 13-25, jan./abr. 2010.

FÁVERO, M. H. Psicologia e conhecimento: subsídios da psicologia do desenvolvimento para a análise de ensinar e aprender. Brasília, DF: Editora Universidade de Brasília, 2005.

FOUCAULT, M. Vigiar e punir - nascimento da prisão. Petrópolis: Vozes, 1999.

GALLO, S. Disciplinaridade e transversalidade. In: ALVES-MAZZOTTI, A. J. et al. (Orgs.).Linguagens, espaços e tempos no ensinar e aprender/Encontro Nacional de Didática e Prática de Ensino (ENDIPE). Rio de Janeiro: DP \& A, 2000, p. 165-179.

GEEVERGHESE, M. A escola entra na roda. In: TUBES, E.; PRESTES, Z.; BARTHOLO, R. (Orgs.). De rodas, varejeiras e outros jeitos de aprender e ensinar. Rio de Janeiro: e-papers, 2016, p. 35-45.

GOMES, K.; NOGUEIRA, S. Ensino da arte na escola pública e aspectos da política educacional: contextos e perspectivas. Ensaio: Avaliação e Políticas Públicas em Educação, Rio de Janeiro, v. 16, n. 61, p. 583-596, out./dez. 2008. 
GONÇALVES, M. A. Sentir, pensar, agir: corporeidade e educação. Campinas: Papirus, 2010.

GRAVATÁ, A., PIZA, C.; MAYUMI, C.; SHIMAHARA, E. Volta ao mundo em 13 escolas. São Paulo: Coletivo Educação, 2013. Disponível em: $<$ http://educacaosec21.org.br/wp-content/uploads/2013/10/131015 Volta_ao mundo_em_13 escolas.pdf > Acesso em: nov. 2014.

ILLICH, I. Sociedade sem escolas. Petrópolis: Vozes, 1985. Disponível em: $<$ https://we.riseup. net/assets/71202/illich-sociedade-sem-escolas.pdf $>$. Acesso em: out. 2014.

LEITE, M. I. A criança desenha ou o desenho criança? A ressignificação da expressão plástica de crianças e a discussão crítica do papel da escrita em seus desenhos. In: OSTETTO, L.; LEITE, M. I. (Orgs.). Arte, infância e formação de professores. 5. ed. Campinas: Papirus, 2004, p. 61-77.

LÖWY, M. As aventuras de Karl Marx contra o Barão de Munchhausen: marxismo e positivismo na sociologia do conhecimento. São Paulo: Busca Vida, 1987.

LÖWY, M. Ideologias e ciências sociais: elementos para uma análise marxista. São Paulo: Cortez, 2003.

MACHADO, R. Introdução. In: FOUCAULT, M. Microfísica do poder. Rio de Janeiro: Edições Graal, 2011, p. VII-XXIII.

MAGALHÃES, C.; PONTES, F. Criação e manutenção de brinquedotecas: reflexões acerca do desenvolvimento de parcerias. Psicologia: Reflexão e Crítica, v. 15, n. 1, p. 235-242, 2002.

MAHEIRIE, K.; SMOLKA, A. L..; STRAPPAZZON, A. L.; CARVALHO, C. S. ; MASSARO, F. K. Imaginação e processos de criação na perspectiva histórico-cultural: análise de uma experiência. Estudos de Psicologia, Campinas, v. 32, n. 1, p. 49-61, mar. 2015.

MARX, K.; ENGELS, F. (2010). A ideologia alemã. São Paulo: Martin Claret. (3ª reimpressão).

MARTINS. M. C. Mediações culturais e contaminações estéticas. Revista GEARTE, v. 1, p. 248-264, 2014.

MOREIRA, A. Brincante é um estado de graça: sentidos do brincar na cultura popular. Dissertação (Mestrado em Processos de Desenvolvimento Humano e Saúde) - Instituto de Psicologia, Universidade de Brasília, Brasília, DF, 2015.

MORGADO, J. C. Democratizar a escola através do currículo: em busca de uma nova utopia... Ensaio: Avaliação e Políticas Públicas em Educação, v. 21, n. 80, p. 433-448, jul./set. 2013.

PRADO, K.; TRISOTTO, S. O corpo problematizado de uma perspectiva histórico-política. Psicologia em Estudo, Maringá, v. 13, n. 1, p. 115-121, jan./mar. 2008.

PUPO, M. L. Mediação artística, uma tessitura em processo. Urdimento - Revista de Estudos em Artes Cênicas, v. 2, n. 17, p. 113-121, 2011.

SANTOS, P.; RAMOS, A. P. Currículo, conhecimento e democratização: fluxos de sentido na Educação Básica. Espaço do currículo, v. 6, n. 1, p. 157-170, jan./abr. 2013. 
SCHROEDER, S. C.; SCHROEDER, J. L. Apropriação da música por crianças pequenas: mediação, sentidos musicais e valores estéticos. In: Smolka A. L.; Nogueira A. L. H. (Orgs.). Emoção, memória, imaginação - a constituição do desenvolvimento humano na História. São Paulo: Mercado das Letras, 2011, p. 57-83.

SCHWEDE, G.; ZANELLA, A. V. Olhares de crianças a relevar a polifonia da cidade. Psico-USF, Bragança Paulista, v. 18, p. 395-406, 2013.

SILVA, D. N. Educação, ludicidade e corporeidade: pedagogia: módulo 4, v. 4 - EAD, / Elaboração de conteúdo: Ilhéus: EDITUS, 2011.

SILVA, D. N. Imaginação, criança e escola. São Paulo: Summus, 2012.

SILVA, D. N.; ABREU, F. (Orgs.). Vamos brincar de quê? São Paulo: Summus, 2015.

SILVA, D. N.; COSTA, M.; ABREU, F. Imaginação no faz de conta: o corpo que brinca. In: SILVA, D. N.; ABREU, F. Vamos brincar de quê? São Paulo: Summus, 2015, p. 111-131.

SILVA, D. N. H.; TEJERINA, J. C.; BARBATO, S. La imaginación creadora: aspectos histórico-genealógicos para la reconsideración de una psicología de la actividad y la mediación estética. Estudios de Psicología, España, v. 31, p. 253-277, 2010.

SILVA, J. C. Utopia positivista e a instrução pública no Brasil. Revista HISTEDBR On-line, Campinas, n. 16, p. 10-16, dez. 2004. Disponível em: <http://www.histedbr.fe.unicamp.br/revista/revis/revis16/art2_16.pdf $>$. Acesso em: jan. 2015.

SILVA, L.; GUIMARÃES, A.; VIEIRA, C. E.; FRANCK, L.; HIPPERT, M. I. O brincar como portador de significados e práticas sociais. Revista do Departamento de Psicologia UFF, Niterói, v. 17, n. 2, p. 77-87, 2005.

SOUZA, F. O corpo dança: con(tra)dições e possibilidades de sujeitos afásicos. 2001. Dissertação (Mestrado em Educação) - Faculdade de Educação, Universidade Estadual de Campinas, SP, 2001.

SOUZA, S. J. Fotografar e narrar: a produção do conhecimento no contexto da escola. Cadernos de Pesquisa, São Paulo, n. 116, p. 61-80, Julho 2002 .

TIRIBA, L. “O Corpo na Escola: proposta pedagógica”. In: HTTP://www.redebrasil.tv.br/salto Série “O Corpo na Escola, Salto para o Futuro”, abr. 2008.

THIESEN, J. S. (2013). Currículo interdisciplinar: contradições, limites e possibilidades. In: PERSPECTIVA, Florianópolis, v. 31, n. 2, 591-614, maio/ago.

TONET, I. Método científico: uma abordagem ontológica. São Paulo: Instituto Lukács, 2013.

TUNES, E. O silêncio ou a profanação do outro. In: Sem escola, sem documento. Rio de Janeiro: e-papers, v. 1, 2011, p. 15-29.

UGARTE, M. C. D. O corpo utilitário: da revolução industrial à revolução da informação. In: IX Simpósio Internacional Processo Civilizador: Tecnologia e Civilização, 2005, Ponta 
Grossa, 2005, p, 01-08. Disponível em: http://www.uel.br/grupo-estudo/processoscivilizadores/portugues/sitesanais/anais9/artigos/mesa_redonda/art5.pdf Acesso em: maio de 2017.

VIGOTSKI, L. S. Psicologia da Arte. São Paulo: Martins Fontes, 1999.

VIGOTSKI, L. S. Psicologia pedagógica. São Paulo: Artmed, 2003.

VIGOTSKI, L. S. Imaginação e criação na infância. São Paulo: Ática, 2009.

Submissão em: 30/12/2016

Aceite em: 23/02/2017

Marina Teixeira Mendes de Souza Costa é doutoranda em Processos de Desenvolvimento Humano e Saúde - Instituto de Psicologia - Universidade de Brasília. Professora da Secretaria de Estado de Educação do Distritoo Federal (Educação Infantil e Series Iniciais). Endereço: SQS - 212 - D - 412. CEP 70275-040 Brasília/ DF, Brasil. E-mail: mtmscosta@hotmail.com

Daniele Nunes Henrique Silva é professora Doutora do Programa de Pós-graduação em Processos de Desenvolvimento Humano e Saúde, Departamento de Psicologia Escolar e do Desenvolvimento - Universidade de Brasília. Pesquisadora vinculada ao Grupo de Pesquisa Pensamento e Linguagem (GPPL/UNICAMP) e vice-líder do Grupo de Pesquisa Pensamento e Cultura (GPPCULT/UnB).

E-mail: daninunes74@gmail.com

Eva Aparecida Pereira Seabra da Cruz é pós-doutoranda em Processos de Desenvolvimento Humano e Saúde - Universidade de Brasília. Doutora em Teoria Literária e Literatura Comparada pela Universidade de São Paulo. Bolsista Capes/PNPD no Programa de Pós-Graduação PGPDS, Instituto de Psicologia, Universidade de Brasília. E-mail: evaleones@gmail.com

Patrícia Lima Martins Pederiva é professora do Departamento de Métodos e Técnicas da Faculdade de Educação da Universidade de Brasília e do Programa de PósGraduação em Educação da UnB. Líder do GEPPE - Grupo de Estudos e Pesquisas em Práticas Educativas. E-mail: pat.pederiva@gmail.com 